\title{
Composite tribotechnical materials for autotractors assemblies
}

\author{
Khurshidbek Nurmetov ${ }^{*}$, Alimjon Riskulov, and Jamshed Avliyokulov \\ Tashkent State Transport University, Tashkent, Uzbekistan
}

\begin{abstract}
This article is devoted to developing composite tribotechnical materials based on thermoplastic matrices for designs of autotractor units optimized for service life, safety, and ergonomics. Also, the characteristics, parameters, and application of the obtained composite materials are given.
\end{abstract}

\section{Introduction}

In a wide range of machine-building materials, a special role belongs to polymer composites, which have several significant advantages compared to other types of materials: high specific strength, corrosion resistance, multi-cycle resistance, the processability of processing into products, and the ability to repeatedly recycle.

Machine builders are paying increasing attention to new generation materials nanocomposites, which, according to the complex of strain-strength, tribotechnical, thermophysical, protective, and other characteristics, are superior to traditional materials based on high molecular weight matrices.

Specific design solutions of automotive units of different functional purposes make it necessary to develop tribotechnical materials that differ in characteristics [1-8]. Antifriction composites designed to manufacture shock absorber piston seals must combine high wear resistance, heat resistance, and stability of the linear thermal expansion coefficient under conditions of exposure to increased temperatures, shock-absorbing liquid, impact loads with reversible movement. Wear of this coupling has the character of fatigue activated by thermal oxidation processes.

Metal plastic bearings are used as guides in single-tube shock absorbers, in which the working layer is a composite material based on polytetrafluoroethylene. Such bearings are expensive and require special pipe attachment techniques.

Based on the above, the aim of this work was to develop composite tribotechnical materials based on thermoplastic matrices for designs of autotractor units optimized in terms of service life, safety, and ergonomics.

To achieve this goal, the following tasks were achieved:

1. Investigate the effect of the structure on the tribotechnical characteristics of thermoplastic matrix-based composites.

2. Develop compositions of composite tribotechnical materials and technology for manufacturing elements of optimized units for agricultural and automotive machinery.

*Corresponding author: kh_tari@mail.ru 


\section{Methods}

The tribotechnical materials used for the manufacture of seals shall ensure the specified tightness of the movable joint in difficult operating conditions, combining the effects of abrasive particles, elevated temperatures, and alternating loads. Damage of working surface of one of parts of coupling (seal or rod) changes damping characteristics of shock absorber due to leakage of working medium of their working cavity.

Composite tribotechnical materials based on structural thermoplastics have been developed for manufacturing parts of piston seals and guides. The principle of multilevel modification proposed in [6], as well as the deformation model of the sealant developed by Professor Pinchuk L.S. [10] and used in the creation of movable and static seals based on carbon composite materials [9], was used as a methodological approach in their development.

As base materials, aliphatic polyamides (PA6, PA11) were used, which best meet the complex criterion combining the given level of strength and thermophysical characteristics, processability, availability, and relatively low cost. Combinations of nanosized and fibrous fillers were used to enhance the performance of the polyamides, as which carbon of detonation synthesis (ultradisperse diamond-containing carbon) and colloidal copper obtained by thermolysis of the precursor in the polymer melt were used.

The combination of low-size fillers of different compositions made it possible to realize a synergistic effect of increasing strength, adhesion characteristics, and resistance to thermo-oxidizing media. The latter is important for coatings operated at elevated temperatures $\left(\sim 79-100^{\circ} \mathrm{C}\right)$ for a long time (up to 100 thousand $\mathrm{km}$ of mileage for $4-5$ years).

It is known that low-dimensional modifiers such as ultradisperse diamond-containing carbons, sialons, ceramics, zeolites, and the like have a high surface activity which results in the formation of ordered quasicrystalline structures in the polymer matrix volume that alters the characteristics of the starting polymer [11-16]. Mechanism of arrangement of predominantly amorphous part of macromolecules is associated with polarizing action of nanoparticle charge [16] and adsorption interaction at the matrix-filler interface [17].

\section{Results and Discussion}

The greatest effects are achieved in non-polar matrices, which are strengthened due to the formation of a specific bulk structure from nano areas adjacent to the modifier particle and having dimensions up to 10 or more molecular layers [16]. In polar polyamide matrices, the observed effects are noticeably lower due to the competition of hydrogen bonding processes between macromolecules providing physical, mechanical, and thermophysical characteristics and adsorption bonds of amide groups with active nanofill centers that prevent the formation of intermolecular hydrogen. Therefore, the hardening effect of aliphatic polyamides (PA6, PA66, PA11) is 5-10\% when modified with copper nanoparticles [18] and 10-12\% when nanocarbon [2] is introduced. In addition, the effect of increasing thermal oxidation resistance after 800-1000 hours of exposure at elevated temperatures is reduced due to the formation of macrodefects in the form of cracks sprouting from the surface of the sample deep and having dimensions larger than those of the reinforcing ordered regions in the composite.

During the studies, the features of the strength and thermophysical characteristics of composites modified by a combination of nanosized fillers and reinforcing fibers were used. Studies have shown that the combined modification of polyamide (PA6) with ultradisperse diamond-containing carbon (UDCC) and nanosized copper not only improves 
strength characteristics but also keeps them at a sufficiently high level under conditions of thermo-oxidative aging (Figure 1).

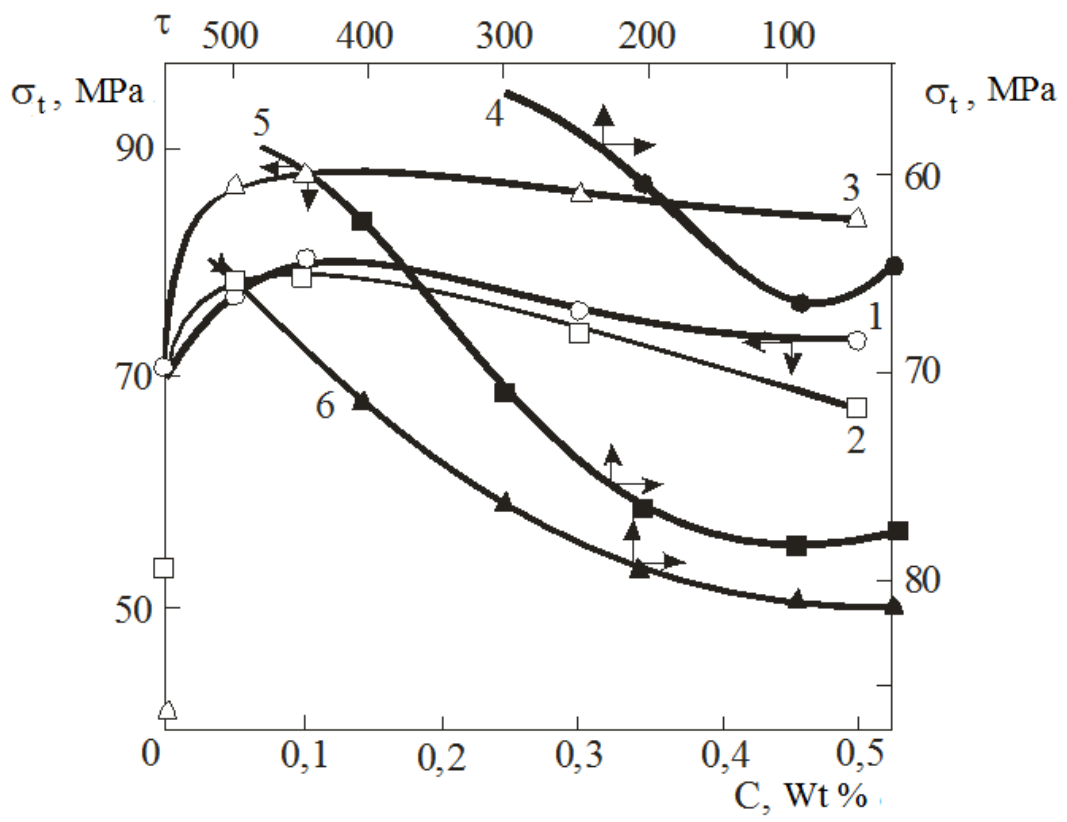

Fig. 1. Dependence of tensile breaking stress $\sigma_{t}$ on filler content (1-3) and thermal oxidation time $\tau$ at $150{ }^{\circ} \mathrm{C}(4-6)$ for initial polyamide PA6 (4) and modified UDCC $(1,5)$, nanodisperse copper - NC (2), a mixture of UDCC and $\mathrm{NC}(50: 50)(3,6)$. Content of nanofill in composites $(5,6)$ is $0.1 \mathrm{wt} \%$.

It should be noted that the strength change curves of composites containing nanodispersed copper in combination with UDCC (Fig. 1, curve 6) and UDCC (Fig. 1, curve 5) have a gentle character without a pronounced fracture, which indicates a significant effect of the structural factor on the process of thermal oxidation [4]. In addition, in a composite containing a mixture of nanofill agents, a copper-copper-containing compound phase transition is observed, which ensures the prolongation of the antioxidant effect. According to the literature, copper compounds have an intense antioxidant effect in polyamide-based compositions [19].

A similar hardening effect when a combination of UDCC and nanodispersed copper (NC) is introduced is characteristic of P11 polyamide (Rilsan). The complex filler also has a beneficial effect on the adhesion characteristics of the composite material, especially when exposed to thermal oxidizing media (Table 1).

Co-incorporation of nanoscale modifiers into the polyamide matrix improves adsorption characteristics of the surface layer of the sample. This effect is probably due to the interaction of weak force fields of nanomodifiers on the polarization of low molecular weight hydrocarbons. The thickness of the boundary layer of the lubricant adsorbed by the friction surface increases. A similar effect is noted in [9] when using fluorine-containing oligomers as functional components.

The studies carried out served as the basis for developing a composite tribotechnical material for coating the inner surface of the shock absorber cylinder instead of guides made of metallofluoroplastic tape. Considering that the tribotechnical coating is operated under limited lubrication conditions (disposable during assembly), a low melting polyolefin with a melting point significantly lower $\left(120^{\circ} \mathrm{C}\right)$ than the melting point of the matrix material $\left(220^{\circ} \mathrm{C}\right)$ was introduced into the polyamide matrix. 
Table 1. Adhesive characteristics of composite materials

\begin{tabular}{|c|c|c|c|c|c|c|c|c|c|}
\hline \multirow{2}{*}{$\begin{array}{c}\text { Polymer } \\
\text { matrix }\end{array}$} & \multicolumn{3}{|c|}{ Nanomodifier } & \multicolumn{5}{c|}{ Adhesive strength, $\mathrm{n} / \mathrm{m}$} \\
\cline { 2 - 9 } & UDCC & NC & UDCC+NC & \multicolumn{2}{|c|}{ Steel 08 (boiling) } & \multicolumn{3}{c|}{ Aluminum } \\
\hline PA6 & 0.00 & 0.00 & 0.00 & 160 & 160 & 160 & 330 & 330 & 330 \\
& 0.01 & 0.01 & 0.01 & 200 & 190 & 210 & 340 & 340 & 350 \\
& 0.05 & 0.05 & 0.05 & 230 & 200 & 230 & 350 & 345 & 360 \\
& 0.10 & 0.10 & 0.10 & 280 & 200 & 270 & 340 & 350 & 360 \\
\hline P11 & 0.00 & 0.00 & 0.00 & 160 & 160 & 160 & 310 & 310 & 310 \\
(Rilsan) & 0.01 & 0.01 & 0.01 & 210 & 180 & 220 & 320 & 330 & 340 \\
& 0.05 & 0.05 & 0.05 & 240 & 250 & 230 & 340 & 350 & 350 \\
& 0.10 & 0.10 & 0.10 & 290 & 260 & 270 & 350 & 360 & 380 \\
\hline
\end{tabular}

Polyamide polyolefin composites are widely used as structural and tribotechnical materials [20-21]. To increase thermodynamic compatibility of PA6 and PE, various technologies of activation of polyolefin particles are used - grafting of functional groups [20], modification with $\gamma$ - radiation [21]. We used the principle of introducing a compatibilizer - a component compatible with a polyamide matrix and a polyolefin modifier. As such a component, a disperse powder of polyvinyl alcohol was used, the macromolecule of which includes polar hydroxyl groups - OH. Due to the close structure of the molecular chain of polyvinyl alcohol (PVA) and polyethylene (PE), a thermodynamically equilibrium system of PVA + PE is formed; on the other hand, due to the presence of polar groups, the interaction of the macromolecule PA6 and PVA occurs with the formation of a spatial network of hydrogen bonds. Alloying the mixture of PA6 (PA12, P11) -PE with a compatibilizer in combination with nanodispersed carbon and copper particles made it possible to obtain coatings with the necessary combination of physical-mechanical, adhesion, and tribotechnical characteristics that satisfy the requirements for the operation of shock absorbers in conditions of temperature drop from 40 to $+100^{\circ} \mathrm{C}$. The compositions of the developed composite materials are given in Table 2 .

Table 2. Composition of composite tribotechnical materials for coating on tubular billets

\begin{tabular}{|l|c|c|c|}
\hline \multirow{2}{*}{ Component } & \multicolumn{3}{c|}{ Content by Brand } \\
\cline { 2 - 4 } & KAMA-1 & KAMA-2 & KAMA-3 \\
\hline Polyamide & 94.47 & 88.85 & 69.4 \\
Polyolefin & 5 & 10 & 25 \\
Polyvinyl alcohol (PVA) & 0.01 & 0.1 & 0.5 \\
Ultrafine Carbonaceous Product (UDCC) & 0.01 & 0.025 & 0.05 \\
Dry grease & 0.5 & 1.0 & 5.0 \\
Nanodispersed copper & 0.01 & 0.025 & 0.05 \\
\hline
\end{tabular}

We used powdered products obtained by cryogenic dispersion of granules PA6, P12, and P11 (Rilsan) as the polyamide matrix. Dry lubricants were colloidal graphite C-1, disulfide molybdenum $\mathrm{MoS}_{2}$, or a mixture thereof. According to traditional technology, the coating on the working surface was applied by the fluidized bed method [22-25]. The resulting workpiece was calibrated with a cutting tool to obtain predetermined geometric dimensions. The developed coatings have high adhesion and tribotechnical characteristics. 


\section{Conclusion}

In conclusion, the following may be noted as a summary:

1. The carried out system studies of the features of operation of automobile shock absorbers made it possible to establish the corrosion-mechanical nature of wear of their movable joints and to propose an integrated approach to increasing their operational life, consisting in the development of functional materials that take into account the specific features of contact interaction. Physical-mechanical and tribotechnical characteristics of polyamide-based composite materials (PA6, P11) modified with polyethylene (PE) depending on the type of compatibilizers (nanosized particles, polyvinyl alcohol) were investigated. The complex influence of nanomodifiers on the properties of composites is shown.

2. The composition of the composite material for antifriction coating with improved tribotechnical and adhesion characteristics has been developed, which is not inferior to the best foreign analogues (Rilsan, ELF ATOCHEM). Polyamide-based composite coatings have been used to manufacture an industrial batch of insert cartridges for vehicles.

\section{Acknowledgment}

The authors of this research work express sincere thanks to Professor Struk V.A. for his practical support in conducting experimental research and obtaining results.

\section{References}

1. Manson, J. Polymer Mixtures and Composites p. 440, Chemistry, (1979)

2. Kravchenko V.I. Structure and technology of composite materials for structures of cardan transmissions of the Belkard-2000 series, p. 150, Grodno, (2001)

3. Red L.A. Features of the working processes of the pneumatic brake drive of cars at low temperatures, p. 27, (1987)

4. Pilgui V.B. Improvement of membrane actuators of pneumatic brake drive of cars, $p$. 24.

5. Mamonchik A.I. Hydraulic double-tube shock absorbers: disassembled or rolled Automotive industry, № 9, pp. 16-17, (1999)

6. Popov Yu.V. Design of universal hinges and driving shafts, Per with English, Engineering, p. 463, (1984)

7. Renner T.E. Accurate Tire Models for Vehicle Handling Using the Empirical Dynamics Method, International ADAMS User Conference, Orlando, Florida, June 19-21, pp. 35-38, Orlando, (2000)

8. A nonlinear viscoelastic bushing element in multibody dynamics, Computational Mechanics, 17, pp. 287-296, (1996)

9. Gorbatsevich G.N. Structure and technology of carbon sealing materials for static and movable seals, p. 140, Polotsk, (2001)

10. Pinchuk L.S. Hermeticology, Navuka i tehnika, p. 216, (1992)

11. Struk V.A. State and prospects of development of nanotechnologies and nanomaterials in the Republic of Belarus and the Russian Federation, Properties of the National Senior Seminary on nanostructured materials, p. 6-21, Nanjing, (2002)

12. Dan Li. Synthesis and interrelation properties of nanoscale layered tetratitanate, Jornal of material Chemistry, 12, pp. 1796-1799, (2002)

13. Dan Li, Xin Wang, Lude Lu, Xujie Yang. Rapid preparation of porous FeaOs/SiCb nanocomposites via an organic precursors, Materials Bulletin, 36, pp. 2437-2442, (2001) 
14. Gang Xiong. Characterization and size dependent magnetic properties of $\mathrm{Ba} 2, \mathrm{CO} 2$, Fe24, O4i nanocristals synthesized through a sol-get method, Jornal of material Science, 35, pp. 931-936, (2000)

15. Liopo V.A. To the mechanism of action of ultra-dispersed geomodifiers, Bulletin of the Yanka Kupala State University. Ser. 2, № 2(20), pp. 52-62, (2003)

16. Avdeychik S.V., Liopo V.A., Struka V.A. Introduction to the physics of nanocomposite machine-building materials, Grodno: GGAU, p. 439, (2009)

17. Skaskevich A.A. Structure and technology of low-filling machine-building materials based on structural thermoplastics modified with carbon nanoclusters, p. 115, Minsk, (2000)

18. Kattakulov F., Muslimov T., Khusainov A., Vokhidov O., Sultanov S. Water resource saving in irrigation networks through improving the efficiency of reinforced concrete coatings, IOP Conf. Ser. Mater. Sci. Eng. 883(1), 012028 (2020)

19. Riskulov A.A. Development of machine-building materials based on metal polymers,p. 201, Gomel, (1990)

20. Goldade V.A. Inhibitors of wear of metal polymer systems, p. 240, Chemistry, (1993)

21. Krivoguz, Yu.M. Technology of functionalized polyolefins and composite materials based on them, Materials, technologies, tools. Special, 3(2), p. 80, (1998)

22. Rybakov V., Jos V., Raimova I., and Kudryavtsev K. Modal analysis of frameless arches made of thin-walled steel profiles. IOP Conf. Ser. Mater. Sci. Eng. 883, (2020).

23. Aderich V.N. Effect of radiation-chemical functionalization of polyethylene on the structure and tribotechnical properties of polymer mixtures "polyamide-polyethylene № 2(21), pp. 167-173, (2000)

24. Dovgilo V.A. Composite materials and coatings based on dispersed polymers ./V.A. Dovgilo O.R. Navuka i tekhnika, p. 256, (1992)

25. Riskulov A.A. Tribotechnical coatings based on polymer matrices for automotive and agricultural machinery, Mechanical engineering and technosphere of the XXI century: Collection of works of the XVI international scientific and technical conference in Sevastopol, 4, Donetsk: DonNTU. 2009. pp. 67-73, (2009) 